\title{
Thermochromic offset ink - paper interactions and print biodegradation
}

\author{
Marina Vukoje, Mirela Rožić \\ University of Zagreb, Faculty of Graphic Arts, Getaldiceva 2, 10000 Zagreb, Croatia \\ *E-mail: mirela.rozic@grf.hr
}

\begin{abstract}
:
This study examines the adhesion and interactions between thermochromic offset ink and different papers as well their role in papers and prints biodegradation. Obtained results show that biodegradation of prints depends upon the adhesion, i.e. lower adhesion will result in reduction of biodegradation rate, while the strong adhesion will result in better paper degradation. Reactions between paper and thermochromic ink will form different prints properties due to different affinity of paper for ink while interactions between them will affect the prints biodegradation. When the ink is applied on paper, the polar constituents of paper will react with polar constituents of ink. Smaller amount of polar components of paper will give a print with polar character.
\end{abstract}

Key words: Thermochromic offset ink, paper - ink interactions, adhesion, biodegradation

\section{Introduction}

Printing inks are coloured complex mixtures, liquids or pastes, mostly consisted of colorant, binder (resins), solvent and additives. Additives are often different chemical substances for the improvement of printing ink performance, such as catalysts, antioxidants, adhesion promoters, amine stabilizers, antifoam agents, biocides, chelating agents, dispersing agents, siccatives for optimized drying, flow agents, gallants, ink stabilizers, optical brighteners, photoinitiators, waxes, UV stabilizers, and wetting agent. Biocides are needed for aqueous inks to control microbial growth, but in offset letterpress technology can be used in fountain solutions as well $[1,2]$. Chemical composition of printing inks and their physical property mostly differs due to printing process that they are intended for. When they are applied to substrate, the ink must be converted to solid state. The binder dries and binds the colorants to the substrate. The drying of printing inks must be achieved as quickly as possible and it can be performed by physical (evaporation) and chemical (oxidation, radiation-induced curing) means or a combination of both [1]. Sheet-fed offset inks set by oxidative polymerisation of the drying oils and alkyds. Drying is commonly accelerated using oxidative metal-ions or absorbing oils in the ink formulation to concentrate the ink faster, or by the use of IR or UV drying [3].

One of the main functions of printing inks is to adhere on the printing substrate and remain there for the whole lifespan of print. Adhesion is the interatomic and intermolecular interaction 
at the interface of two surfaces. It is a multi-disciplinary topic which includes surface chemistry, physics, rheology, polymer chemistry, stress analysis, polymer physics and fracture analysis [4]. Adhesion of printing inks onto the printing substrate depends upon colorants, solvents and binders. The influence of colorants on ink adhesion mostly depends upon their compatibility with the binder system, their type, percentage and degree of dispersion in the final ink. Adhesion is influenced by the degree of binder absorption on absorbent (paper) while for non-absorbent substrates, is controlled by the film-forming ability of the binder and the molecular affinity for the substrate. Solvents can influence wettability and absorption of printing ink. Adhesion can also be affected by adding additives in small amounts during manufacturing process in order to improve chemical bonding between printing substrate and ink [1]. The bond strength between the paper surface and polymer depends strongly on the physical and chemical structure of the two surfaces that are in contact. For example, the polymer polarity created by the carboxyl content of adhering polymers, would affect the adhesion strength of the cellulose-polymer bond, where peel strength increases when the carboxyl content increases. Thus, polarity of polymer and cellulose substrate affects the strength [5].

Surface properties of paper (surface energy, absorption, roughness and porosity) of the paper may affect printability of functional inks [6-8]. In addition, appropriate matching of surface energy to ink surface tension (adhesion) becomes important or the print definition and conductivity of functional inks [7]. Ink-paper interactions, including the ink transfer, set- ting and drying processes, have an important role in print production, since they influence both print quality and runnability [9]. Surface interactions between printing ink and paper are of importance during printing, as well as during ink removal in paper recycling as a high adhesion between ink and cellulose might cause problems during ink detachment [10-12].

Thermochromic printing inks undergo changes in colour because of small environmental variations, such as temperature. Thermochromic printing inks have a wide range of applications, and their development is still in progress.
Each of these applications requires a specific set of material properties and deeper understanding of the physical and chemical background. Commercially available thermochromic printing inks based on leuco dyes are consisted of microencapsulated leuco dye-developer-solvent systems and a resin binder [13,14]. The microencapsulated thermochromic pigments usually have medium particle size of a few micrometres, which is about ten times larger than the particle size of conventional pigment particles [13]. Microcapsules are dispersed in a binder. The most widely used system for microencapsulation of thermochromic and photochromic inks involves urea or melamine and formaldehyde systems [15], gelatine-gum arabic and epoxy resins [16]. In thermochromic leuco dye-developer-solvent system thermochromic effects are based on changes of absorption caused by molecular interactions of the incorporated functional dye within its microenvironment [15,17-19]. Leuco dye-developer-solvent systems consist of a chromogenic compound (leuco dye), developer and solvent. The thermochromic effect is caused by the formation of leuco dye-developer complexes in a reversible equilibrium redox reaction between leuco dye and developer. The reaction is triggered by interactions between the complex and the solvent during the melting or crystallization process [17]. The most common electron-donating chromogenic compounds are phenylmethane and fluoran derivatives bearing a lactone ring moiety. In the lactone ring-closed state these so-called leuco dyes or colour formers are either colourless or weakly yellow coloured. Leuco dye-developer-solvent systems are coloured in the solid state and transform on heating above the melting temperature of the solvent into a colourless liquid [20]. Colour developers are usually weak acids (bisphenol A, octyl phydroxybenzoate, methyl p-hydroxybenzoate, 1,2,3-triazoles, and 4-hydroxycoumarin derivatives) while long - chain alkyl alcohols, esters, and acids are commonly used as solvents [18,19].

The aim of the study was to investigate the influence of thermochromic ink - paper interactions on prints biodegradation. Thermocromic ink used in this study is based on vegetable oil polymer resin with $\mathrm{Co}$ and $\mathrm{Mn}$ salts used as catalysts (siccatives) for oxypolymerization 
drying of vegetable oil [21,22]. Microcapsules present in printing ink have polar nature than the classical pigment particles which was confirmed by solvent-thermocromic print interactions using Hansen solubility parameters that rank the solvents based on their estimated interaction capabilities [23].

\section{Materials and Methods}

\subsection{Printing substrate and printing ink}

In preparation of the experiment, five different paper samples were used: synthetic, $33 \%$ recycled, $100 \%$ recycled, bulky and wood free-coated (Table 1). These papers were selected due to their different chemical composition and absorption capacity.

Table 1. Papers used in experiment

\begin{tabular}{|l|l|l|l|l|}
\hline $\begin{array}{l}\text { Paper } \\
\text { type }\end{array}$ & $\begin{array}{l}\text { Abbre- } \\
\text { viation }\end{array}$ & Producer & $\begin{array}{l}\text { Gram- } \\
\text { mage }\end{array}$ & Description \\
\hline $\begin{array}{l}\text { Synthetic } \\
\text { paper }\end{array}$ & $\mathrm{S}$ & Yupo & $\begin{array}{l}73 \\
\mathrm{~g} / \mathrm{m}^{2}\end{array}$ & $\begin{array}{l}\text { Extruded } \\
\text { from poly- } \\
\text { propylene } \\
\text { pellets }\end{array}$ \\
\hline $\begin{array}{l}33 \% \\
\text { recycled } \\
\text { paper }\end{array}$ & $33 \mathrm{R}$ & Mondi & $\begin{array}{l}80 \\
\mathrm{~g} / \mathrm{m}^{2}\end{array}$ & $\begin{array}{l}\text { Containing } \\
\text { 33\% of re- } \\
\text { cycled cellu- } \\
\text { lose fibres }\end{array}$ \\
\hline $\begin{array}{l}100 \% \\
\text { recycled } \\
\text { paper }\end{array}$ & $100 \mathrm{R}$ & $\begin{array}{l}\text { Evercopy } \\
+ \text { Claire- } \\
\text { fontaine }\end{array}$ & $\begin{array}{l}80 \\
\mathrm{~g} / \mathrm{m}^{2}\end{array}$ & $\begin{array}{l}\text { Containing } \\
100 \% \text { of } \\
\text { recycled } \\
\text { fibres, }\end{array}$ \\
\hline $\begin{array}{l}\text { Bulky } \\
\text { paper }\end{array}$ & $\mathrm{B}$ & $\begin{array}{l}\text { Munken } \\
\text { Print } \\
\text { White }\end{array}$ & $\begin{array}{l}80 \\
\mathrm{~g} / \mathrm{m}^{2}\end{array}$ & $\begin{array}{l}\text { Contain- } \\
\text { ing wood } \\
\text { free pulp } \\
\text { and more } \\
\text { than 10\% } \\
\text { mechanical } \\
\text { wood pulp }\end{array}$ \\
\hline $\begin{array}{l}\text { Wood } \\
\text { free coat- } \\
\text { ed }\end{array}$ & WFC & Maxi satin & $\begin{array}{l}115 \mathrm{~g} / \\
\mathrm{m}^{2}\end{array}$ & $\begin{array}{l}\text { High quality } \\
\text { coated paper }\end{array}$ \\
\hline
\end{tabular}

For the printing of paper, samples one leuco dye based thermochromic offset printing ink was used (Chromatic Technologies, Inc.). The activation temperature of thermochromic ink is $45^{\circ} \mathrm{C}$. Below its activation temperature, the print was coloured in green and above its activation temperature the print was coloured in yellow (hereinafter GY). Thermochromic ink is composed of blue microcapsules dispersed in classic yellow offset ink [21]. The printing trials were carried out using Prüfbau Multipurpose
Printability Tester. The quantity of $1.5 \mathrm{~cm}^{3}$ ink was applied on the distribution rollers while printing was carried out with the printing force of $600 \mathrm{~N}$. All the samples were printed in the full tone.

\subsection{Determination of surface properties of paper samples}

Evaluation of surface free energy of paper and paper printed with ink were carried out by contact angle measurements on DataPhysics OCA 30 Goniometer, using Sessile Drop method. By measuring contact angles of standard test liquids (demineralized water, diiodometane and glycerol) whose surface tensions are known (Table 2) it is possible to determine the total solid surface energy and it's dispersive and polar component. Measurements were performed at room temperature $(23.0 \pm 0.2){ }^{\circ} \mathrm{C}$. The volume of droplet was $1 \mu \mathrm{L}$. Contact angle was captured by CCD camera and measured $2 \mathrm{~s}$ after the droplet was formed. Average values of ten drops on different places of the same sample were taken.

Table 2 Surface tensions $(\gamma)$ of test liquids and their dispersive $\left(\gamma^{d}\right)$ and polar $\left(\gamma^{p}\right)$ components

\begin{tabular}{|l|l|l|l|}
\hline \multirow{2}{*}{ Liquid } & \multicolumn{3}{l|}{ Surface tension $/\left(\mathbf{m} / \mathbf{m}^{\mathbf{2}}\right)$} \\
\cline { 2 - 4 } & $\gamma$ & $\gamma^{\mathbf{d}}$ & $\gamma^{\mathbf{p}}$ \\
\hline Water & 72.80 & 21.80 & 51.00 \\
\hline Diiodomethane & 50.80 & 50.80 & 0.00 \\
\hline Glycerol & 63.40 & 37.00 & 26.40 \\
\hline
\end{tabular}

The Owens, Wendt, Rabel and Kaelble (OWRK) calculation method was applied to the contact angle data of test liquids in order to evaluate the parameters of surface free energy $(\gamma)$ and its dispersive $\left(\gamma^{\mathrm{d}}\right)$ and polar $\left(\gamma^{\mathrm{P}}\right)$ components (Table 4). Conducted calculation method is integrated in the software (SCA20, Version 2.01) and automatically carried out. From the obtained $\gamma$, adhesion parameters (surface free energy of the interphase $\left(\gamma_{12}\right)$, work of adhesion $\left(W_{12}\right)$ and wetting coefficient $\left.\left(S_{12}\right)\right)$ were calculated (Table 5). Owens-Wendt model includes the assumption according to which both the dispersive and polar interactions between two phases are equal to the geometric mean expression of $\gamma$ of the individual phase which are in contact with each other, according to Eq. (1) [24]: 


$$
W_{12}=\gamma_{1}+\gamma_{2}-\gamma_{12}
$$

where the subscript refers to surface free energy of the each solid, in our case paper and ink print, and the $\gamma_{12}$ denotes their $\gamma$ of the interphase. Adsorption theory, according to the Dupré approach, which presents the thermodynamic work of adhesion $W_{12}$ between two phases is equal to Eq. (2) [24]:

${ }_{2}=\gamma_{1}+\gamma_{2}-2 \sqrt{\gamma_{1}^{d} \gamma_{2}^{d}}-2 \sqrt{\gamma_{1}^{p} \gamma}$

The wetting coefficient $S_{12}$ is equal to Eq. (3) and indicates that an ink will spontaneously wet and spread on the solid surface if the value is positive or equal to zero, while the negative value implies the lack of spontaneous wetting.

$$
S_{12}=\gamma_{1}-\gamma_{2}-\gamma_{12}
$$

\subsection{Soil burial experiments}

Laboratory soil burial experiments were conducted at room temperature $\left(25 \pm 2^{\circ} \mathrm{C}\right)$ by placing the printed and unprinted paper substrates horizontally in field soils in laboratory glass containers. The paper substrates were buried for 14, 32, 50, 80 and 150 days. The water content of the soil was adjusted to $40 \%$ of its maximum water retention capacity. The commercial available reagent Anaerocult A (Merck) was used in order to allow the development of anaerobic conditions.

\subsection{Visual evaluation}

A method of visual evaluation can be used in order to describe biodegradation as a first indication of microbial activity in the terms of visible surface changes such as formation of holes or cracks, de-fragmentation or changes in colour but it doesn't prove the existence of biodegradation process in terms of metabolism [25]Paper samples were taken from the containers in sampling times and photos of them were taken, in order to visually evaluate the prints degradation over time.

\subsection{Colorimetric measurements}

The colorimetric properties of thermochromic samples were described in the CIELAB colour space. Temperature-dependent colorimetric properties were measured using Ocean Optics USB2000+ spectrophotometer and Ocean Optics Spectra Suite software for the calculation of the CIELAB values $L^{*}, a^{*}, b^{*}$ from measured reflectance in the spectral range of 400-700 $\mathrm{nm}$ (in $1 \mathrm{~nm}$ steps). The D50 illuminant and $2^{\circ}$ standard observer were applied in these calculations. Each sample was thermostated by the Full Cover water block (EK Water Blocks, EKWB; Slovenia) at $23^{\circ} \mathrm{C}$. The temperature of the copper plate surface was varied by circulation of thermostatically controlled water in channels inside the water block, which was assured to be up to $1^{\circ} \mathrm{C}$ accurate in the applied temperature region.

\subsection{Weight loss measurements}

Samples degradation was monitored by measuring the weight of printed-paper samples before and after incubation in the soil containers. The samples were taken out and rinsed with distilled water, in order to remove soil particles from the surface. Then they were dried on air and weighed. The weight loss percentage $(w)$ was calculated according to $E q 4$ :

$$
w=\frac{m_{0}-m_{1}}{m_{0}} \cdot 100
$$

where, $m_{0}$ is the initial weight of the sample, $m_{1}$ is the final weight of the sample after biodegradation.

\section{Results}

\subsection{Determination of surface free energy}

All used paper substrates show hydrophobic surface (water contact angle is greater than $90^{\circ}$ ) (Table 3). The highest hydrophobicity shows bulky paper $\left(120^{\circ}\right)$ due to the presence of lignin in paper [26], while the lowest hydrophobic character was achieved for $33 \%$ recycled paper $\left(91^{\circ}\right)$.

Comparing the characters of thermochromic prints, it can be seen that prints on $\mathrm{B}, 100 \mathrm{R}$, $33 \mathrm{R}$ and WFC papers are hydrophobic while for the print on S, obtained water contact angle $\left(83.19^{\circ}\right)$ indicates a hydrophilic surface. Different prints surface properties can be attributed to the absorption of inks into the paper structure. Synthetic paper is not absorbent, and all 
the components of the printing ink remain on the surface. Smaller water contact angle on the WFC $\left(94.0^{\circ}\right)$ also points to more polar surface. The used thermochromic printing ink is offset, and her main characteristic is hydrophobic property. In addition, the used ink is based on vegetable oil, as confirmed by Vukoje et al., (2017), and contains Co and Mn salts as catalysts (siccatives) necessary for oxypolymerization drying of vegetable oil [22]. In reaction with oxygen from the air, vegetable oils and alkyds, dries by oxypolymerization resulting in formation of polymers with R-O-O-R structure, where $\mathrm{R}$ represents alkyl groups.

Table 3. Contact angles measurements

\begin{tabular}{|l|l|l|l|}
\hline \multirow{2}{*}{ Sample } & \multicolumn{3}{|l|}{ Contact angle $\left./{ }^{\circ}\right)$} \\
\cline { 2 - 4 } & Water & Glycerol & Diiodomethane \\
\hline S & 102.98 & 109.51 & 57.15 \\
\hline B & 120.24 & 118.38 & 55.84 \\
\hline 100R & 119.59 & 119.99 & 48.94 \\
\hline 33R & 91.89 & 104.91 & 55.60 \\
\hline WFC & 100.34 & 118.95 & 61.81 \\
\hline S-GY & 83.19 & 97.056 & 47.75 \\
\hline B-GY & 108.26 & 113.17 & 50.97 \\
\hline 100R-GY & 104.59 & 111.17 & 53.38 \\
\hline 33R-GY & 110.47 & 120.11 & 57.24 \\
\hline WFC-GY & 94.0 & 81.62 & 38.99 \\
\hline
\end{tabular}

Figure 1 provides the calculated values of the surface free energy $(\gamma)$ of unprinted and printed samples. Unprinted papers can be divided into two categories- absorbent (100R, B, 33R) and non-absorbent (S and WFC). Comparing the $\gamma$ values of absorbent papers, it can be seen that $100 \%$ recycled paper has the highest value $\left(29.42 \mathrm{~mJ} \mathrm{~m}^{-2}\right)$, followed by bulky $(26.44 \mathrm{~mJ}$ $\mathrm{m}^{-2)}$ and $33 \%$ recycled paper $\left(23.87 \mathrm{~mJ} \mathrm{~m}^{-2}\right)$. Synthetic paper $\left(23.10 \mathrm{~mJ} \mathrm{~m}^{-2}\right)$ and WFC paper $\left(18.84 \mathrm{~mJ} \mathrm{~m}^{-2}\right)$ have slightly smaller values of $\gamma$.

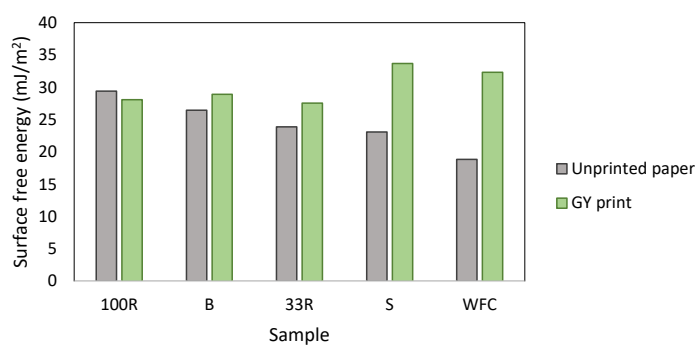

Figure 1. Surface free energy of unprinted papers and prints

Only print on 100R paper has lower $\gamma$ compared to unprinted paper. The prints on other papers have higher value of $\gamma$. The highest differences in $\gamma$ can be noticed for prints on S and WFC papers. This results point that the best ink adhesion was obtained on the surface of $100 \mathrm{R}$ paper. Molecules present on the surface of 100R paper have the highest $\gamma$ and thus they have the highest tendency to reduce it in the interaction with molecules. It can be concluded that in this case, the adhesion forces are higher than the forces of cohesion. In other cases, the surfaces of papers have too low $\gamma$, so the forces of cohesion between the molecules of ink are greater than the adhesion forces. In this case, it can be concluded that ink has poor wettability of surfaces. Specific surface energy of all unprinted paper samples mostly originate from its dispersive component as evident from the Figure 2. The smaller surface free energy $(\gamma)$ of paper will result in its smaller dispersive component $\left(\gamma^{\mathrm{d}}\right)$ (a slight deviation occurs with $S$ paper). All the prints show higher values of $\gamma^{\mathrm{d}}$ compared to unprinted paper samples. The highest values of prints $\gamma^{\mathrm{d}}$ were obtained on non-absorbent papers (S-GY and WFC-GY). For the 100R-GY, the value of $\gamma^{\mathrm{d}}$ was almost the same as for unprinted 100R paper. In the case of B-GY and 33R-GY, the value of $\gamma^{\mathrm{d}}$ was slightly higher compared to unprinted papers.

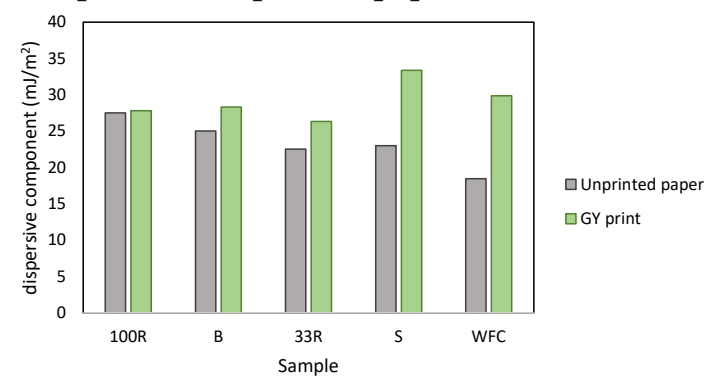

Figure 2. Dispersive component of surface free energy of unprinted papers and prints

Surface free energy of 100R, B and 33R papers have small values of polar components $\left(\gamma^{\mathrm{p}}\right)$, but still higher than polar component of $S$ and WFC paper (Figure 3). 100\% recycled paper has the highest value of polar component than other papers $\left(1.91 \mathrm{~mJ} \mathrm{~m}^{-2}\right)$. 


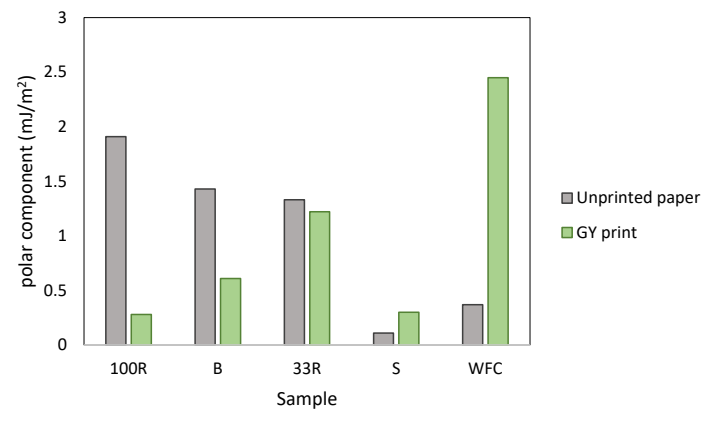

Figure 3. Polar component of surface free energy of unprinted papers and prints

In the case of $100 \mathrm{R}, \mathrm{B}$ and $33 \mathrm{R}$ papers, the polar components of the prints are smaller compared to polar components of the unprinted papers. Even though surface free energies of paper as well as dispersive components of $\boldsymbol{y}$ do not reduce in contact with print, the polar components do (Figs 1, 2, 3). The highest reduction of polar components was in case of 100R paper. This can mean that between $100 \mathrm{R}, \mathrm{B}$ and $33 \mathrm{R}$ paper and thermochromic ink are the most important polar interactions. The polar interactions are the highest with the surface of $100 \mathrm{R}$ paper, while the lowest are in the case of $33 \mathrm{R}$ paper. In the case of $S$ and WFC papers, the polar interactions are higher compared to unprinted papers, which, together with the previous conclusions, indicate a poor adhesion.

Figure 4 shows the calculated values of adhesion parameters. The calculated adhesion parameters can be used to predict the optimal adhesion at the interface. The conditions for the optimal adhesion at the interface between paper and thermochromic printing ink are achieved if the following conditions are met: $\boldsymbol{\gamma}_{12}$ $=0, W_{12}=$ maximal and $S_{12} \geq 0$. The adhesion of ink components to the substrates can be expressed as the sum of works of adhesion for polar and dispersive interaction, giving as a result the overall thermodynamic work of adhesion [27]. Figure 4 shows that optimum adhesion was achieved in the case of $100 \mathrm{R}$ and thermochromic ink interface. The lowest adhesion was achieved in the case of WFC paper and thermochromic ink.

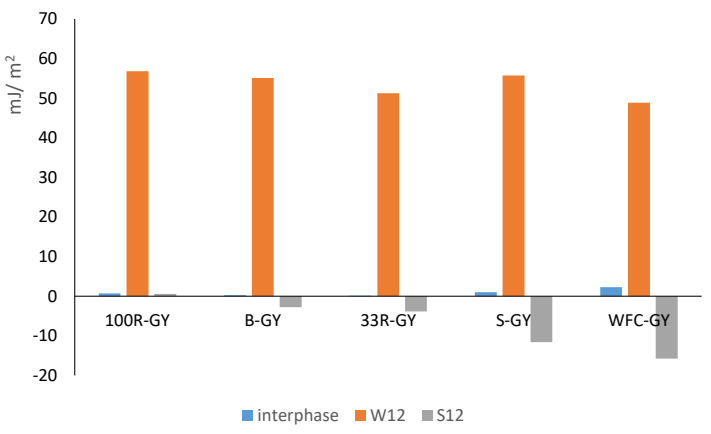

Figure 4. Surface free energies of interphase, work of adhesion $\left(W_{12}\right)$ and spreading $\left(S_{12}\right)$

\subsection{Visual evaluation}

Figs 6 - 10 show visual appearance after prints biodegradation. All the prints show differences in colour, especially after 150 days of biodegradation. From the Figs 8 and 9 it can be seen that the prints on $S$ and WFC paper are damaged during sampling (stretch marks) which points to non-crosslinked network and non-oxidized ink (other samples were not damaged in this way). Moreover, the print on WFC paper shows the most heterogeneous print degradation, which can also be the result of non-crosslinked and non-oxidized ink on the surface of paper.

Results of $a^{*}$ colorimetric values determined on thermochromic prints before biodegradation are presented in Figure 5. In the CIELAB colour space the value $-a^{*}$ represents greenness. The lowest $a^{*}$ value has thermochromic print on $\mathrm{S}$ paper, probably due to highest concentration of ink on the surface. The highest $a^{*}$ values (more positive) are in the cases of $100 \mathrm{R}$ and $\mathrm{B}$ paper probably due to best adhesion.

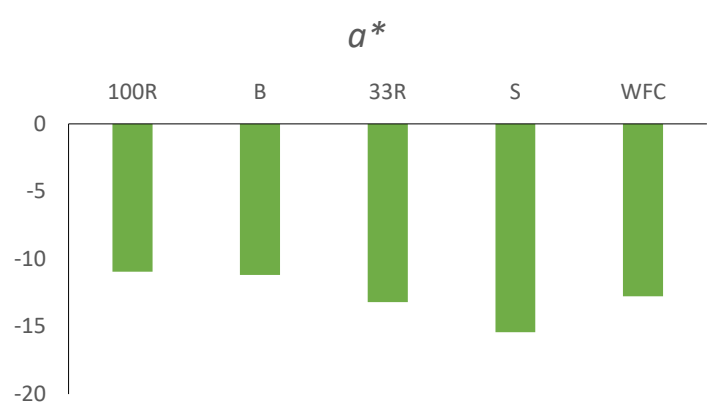

Figure 5. Initial $a^{*}$ colorimetric values of prints 


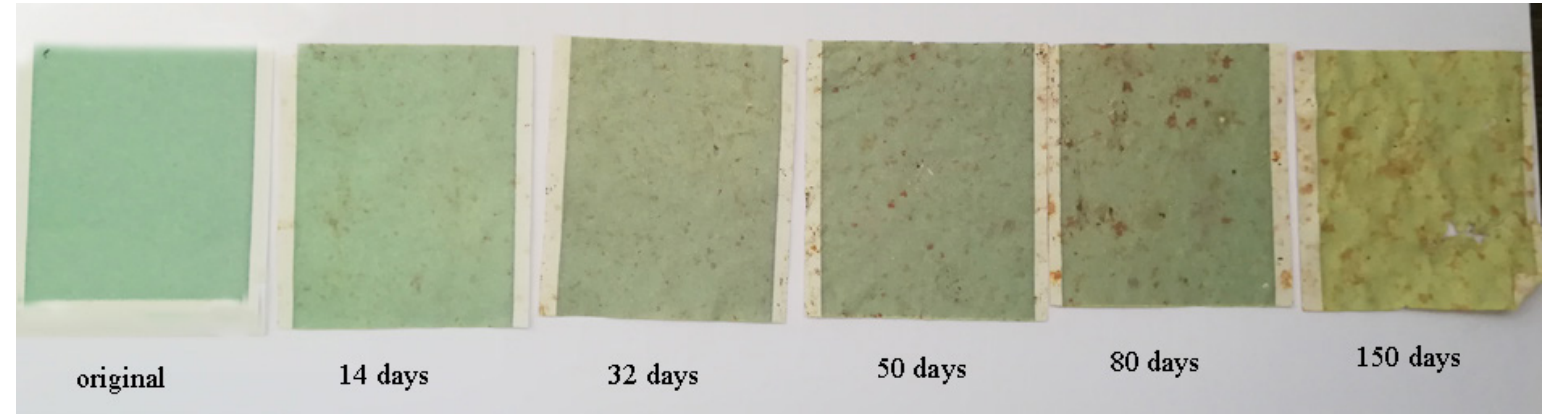

Figure 6. Visual evaluation; $100 \%$ recycled paper - print (100R-GY) before and over 14, 32, 50, 80 and 150 days of biodegradation

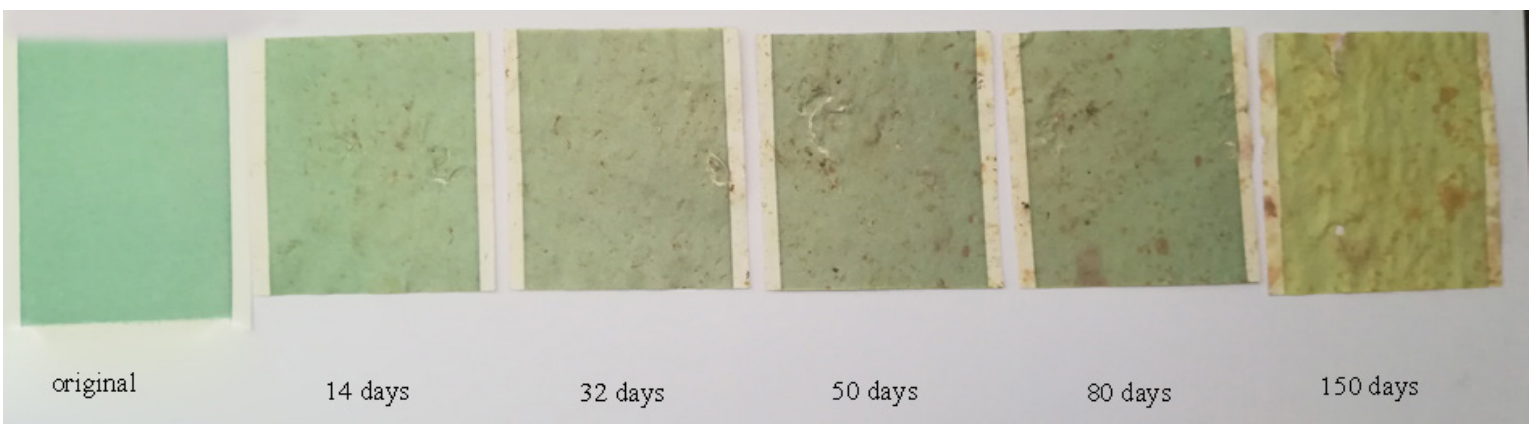

Figure 7. Visual evaluation; Bulky paper - print (B-GY) before and over 14, 32, 50,80 and 150 days of biodegradation

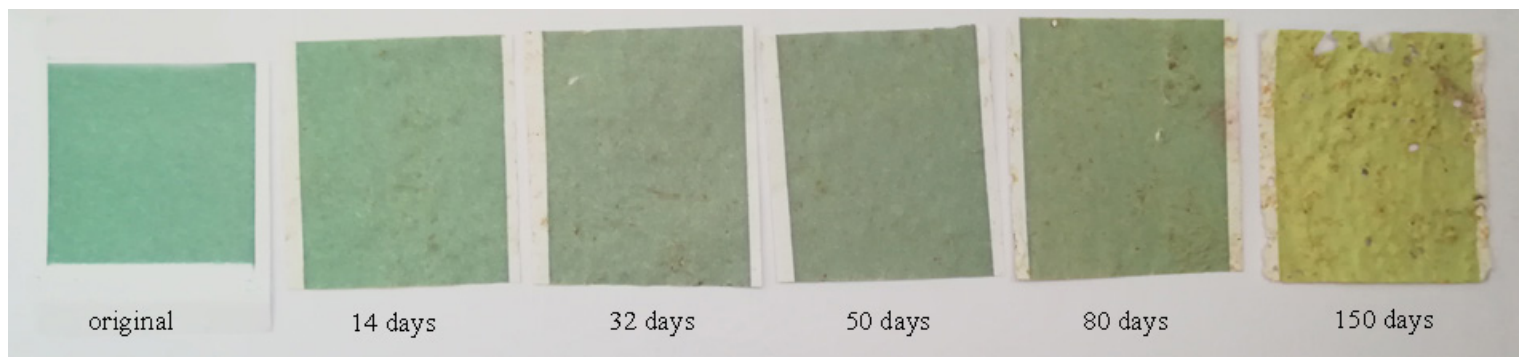

Figure 8. Visual evaluation; 33 \% Recycled paper - print (33R-GY) paper before and over 14, 32, 50, 80 and 150 days of biodegradation

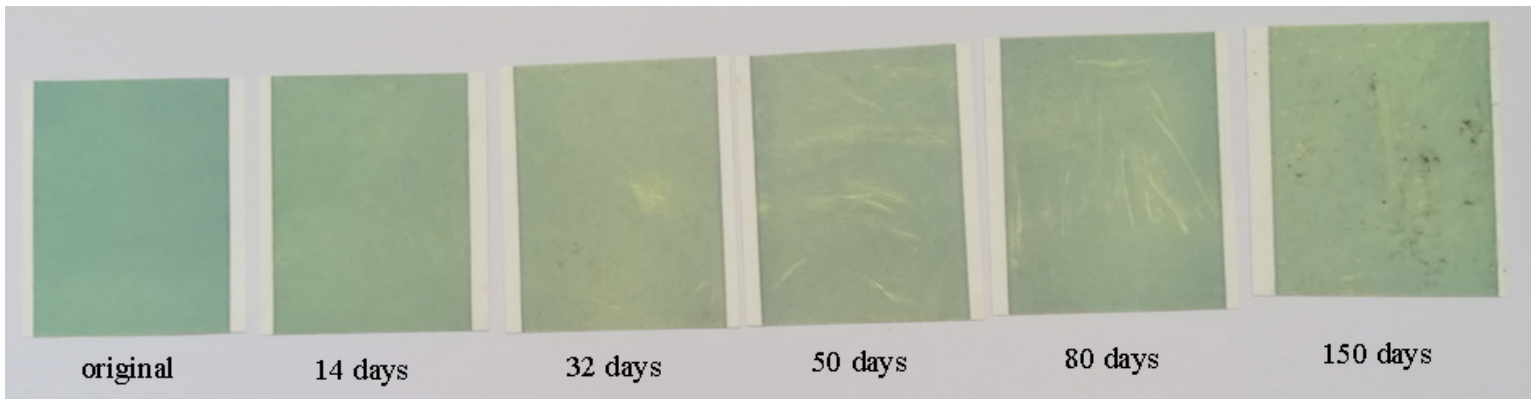

Figure 9. Visual evaluation; Synthetic paper - print (S-GY) before and over 14, 32, 50, 80 and 150 days of biodegradation 
All samples, besides print on $\mathrm{S}$ paper, show noticeable degradation not only of the print colour, but the whole sample (paper) as well, especially after 50 and 180 days of biodegradation. Formation of brown spots can be seen which point to significant degradation, and formation of cracks. The prints during biodegradation are becoming lighter green, and transforming to yellow due to degradation of blue microcapsules present in ink [21]. The activation temperature of used thermochromic ink is $45^{\circ} \mathrm{C}$. Below activation temperature, the print was coloured in green and above its activation temperature the print was coloured in yellow. This behaviour can be explained by the formation of colorant- developer coloured complex in microcapsules (in this case blue coloured) on lower temperatures (below its activation temperature). On heating above the melting temperature of the solvent (above temperature of activation) the solvent in liquid form, causes the breakdown of the colorant - developer coloured complex, the blue colour disappears while yellow colour of classic offset ink appears.

Thus, the shift of colour during degradation from green (combination of blue microcapsules and classical yellow offset ink) towards yellow indicates that deformation of microcapsules (diffusion of components from microcapsules) and / or degradation of the microcapsule occurred [21]. The results of the prints colour change during biodegradation follow the results of the print adhesion strength, except in the case of print on the WFC paper. Specifically, optimal ink adhesion was obtained on the surface of $100 \mathrm{R}$ paper (Figure 4). The print on 100R paper shows the highest degradation, followed by prints on $\mathrm{B}$ and 33R paper and finally on $S$ paper. Even though the lowest adhesion was obtained on the surface of the WFC paper, degradation of the print was the highest. Additionally, better adhesion will result consequently in better degradation (except for print on WFC paper).

Polymerized vegetable oils harden on exposure to oxygen through the oxidation of double bonds to hydroperoxides [28].

Simplified chemical structure of the product of the polymerization reaction is shown in Fig. 11. It results in the formation of three-dimensional networks although some low molecular weight ketones, carboxylic acids, and alcohols are formed in the oxidative polymerization via decomposition of oil hydroperoxides. Polymerized oils are soft and sticky in some cases. According to Shogren et al., (2004), kraft paper coated with oxidatively polymerized soybean and linseed oil was $90 \%-100 \%$ converted to $\mathrm{CO}_{2}$ after 65 days in soil at $30^{\circ} \mathrm{C}$. In our experiment, paper-prints degraded much more slowly [28]. This may be due to slower degradation of classical yellow pigment and / or the addition of alkyd resins.

For the offset printed coated papers, separation of different ink components during ink setting and drying on coated paper may occur $[9,29]$. Oxidation of offset inks is normally based upon the reaction of alkyd resins and vegetable oils [30]. During oxypolymerization of the offset ink on the surface of paper, the cross-linking of the double bonds in the oil and alkyd resins occurs $[3,29]$. Alkyd resins interacts with the coating pigment (kaolin or $\mathrm{CaCO}_{3}$ ) and adsorbs on them [3]. Hydrophilic dispersed pigment surfaces of the coating act as sites for alkyd resins adsorption. This leads to separation of ink vehicle components and prevention of their mutual interactions, which can affect the ink drying. Because of it, the ink on WFC paper is not completely oxidised. Thus, the reaction of alkyd and vegetable oil is hampered, resulting in lower degree of ink oxypolymerization. This behavior can explain higher color degradation of the WFC-GY print, because it is not oxidized and remains soft, the degree of polymerization is lower, allowing bacteria to be better degraded it (i.e. microcapsules). For the print on synthetic paper, all the components of ink are present on the surface of paper. However, since there is no coating pigment present in the synthetic paper, interactions between pigment and alkyd will not appear, while reaction of alkyd and vegetable oil will exist and the print surface will have different properties compared to print on WFC paper. Due to higher amount of ink on the surface of synthetic paper, oxypolymerization of ink will probably be slower, compared to other prints since there is no penetration of the ink binder into the paper structure. In addition, this behaviour would explain the surface energy of the prints and its polarity. The highest values of dispersive components for both prints, S-GY and WFC-GY, 
originate from ink adsorbed on the surface of papers.

The changes in the colour of the prints, probably occurs due to degradation and deformation of the thermochromic microcapsules present in ink as confirmed earlier in the study by [21]. The thicker the polymeric resin layer over the microcapsules is, makes them more protected towards biodegradation, as demonstrated in the previous study by Vukoje et al., (2017). This means that the rate of microcapsule degradation is greater than the rate of biodegradation of the cross-linked oxidized binder (resins + oils). For this reason, the rate of biodegradation of the print on $100 \mathrm{R}$ paper surface is the highest. The higher the absorption of the ink vehicle into the paper is, the faster the rate of print degradation will be. In the case of WFC paper, microcapsules are probably protected with thicker layer of ink resin (vehicle, binder) but it is not completely oxidized and it is not cross-linked, resulting in soft resin, which is more easily for bacteria to degrade it. In the case of S-GY print microcapsules are covered with the thickest layer of the oxidised ink resin resulting in the smallest colour change.

\subsection{Weight loss measurements}

Figure 12 shows the weight loss measurements of unprinted papers during biodegradation. For unprinted papers, it can be seen that the highest weight loss was obtained for WFC paper while the smallest was obtained for $\mathrm{S}$ paper. The rate of biodegradation increases in a row: $33 \mathrm{R}>\mathrm{B}>100 \mathrm{R}$.

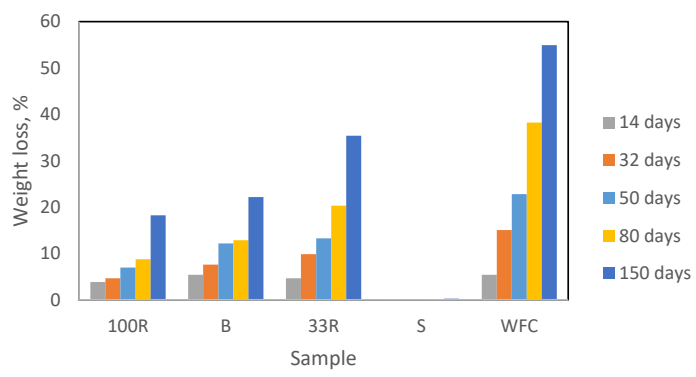

Figure 12. Weight loss measurements of unprinted papers during biodegradation

Figure 13 shows weight loss measurements of printed papers. For print on 100R paper, the best adhesion was achieved. In this case, the rates of biodegradation for unprinted and printed paper slightly differ. The weight loss of samples points to degradation of paper and ink at the same time. In the case of printed B and 33R paper, the prints slow down the rate of biodegradation, somewhat more in the case of print on paper 33R. For the print on WFC paper, the print notably reduces the rate of biodegradation. Accordingly, the lowest adhesion will result in higher reduction of biodegradation rate. The highest rate of biodegradation (the highest weight loss) corresponds to samples where the optimum adhesion was achieved for 100R- GY. Even though the colour degradation was the highest in the case of WFC-GY print, the weight loss point mostly to degradation of microcapsules on the surface of the print. Probably other components of the ink present on the surface of coated paper are more likely difficult to degrade. Unprinted synthetic paper and print on synthetic paper shows almost no changes in weight during sampling time, most likely due to chemical composition of synthetic paper, i.e. polypropylene, since it is resistant to microbial attack $[31,32]$.

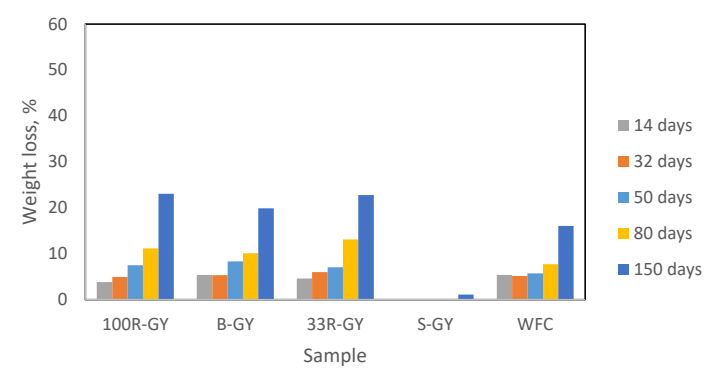

Figure 13. Weight loss measurements of papers with prints during biodegradation

\section{Conclusion}

Thermochromic offset ink - paper interactions play an important role in the papers and prints biodegradation. In order to achieve the best adhesion properties, the paper should have surface free energy somewhat similar to ink, with optimum proportion of dispersive and polar forces. From the obtained results, it can be concluded that biodegradation of prints depends upon the adhesion, i.e. lower adhesion will result in reduction of biodegradation rate, while the strong adhesion will result in better paper degradation. During ink setting onto the paper, reactions between them will form different prints properties due to different affinity of paper for ink. In addition, the interactions 
between paper and ink as well as orientation of the molecules on the surface of the prints will affect the biodegradation. When the ink is applied on paper, the polar constituents of paper will react with polar constituents of ink. Smaller amount of polar components of paper will give a print with polar character. Thus, the paper surface participates in the organization and orientation of the molecules on the surface of the print. The optimum adhesion will influence the whole print (paper and ink) biodegradation.

\section{References}

1. Leach RH. The Printing Ink Manual. 5th ed. Leach RH, Pierce RJ, Hickman EP, Mackenzie MJ, Smith HG, editors. Dordrecht, The Netherlands: Springer; 2007. 1022 p.

2. Pekarovicova A, Husovska V. Printing Ink Formulations. In: Izdebska J, Sabu T, editors. Printing on Polymers. Oxford: William Andrew by Elsevier; 2016. p. 41-55.

3. Rousu SM, Gane PAC, Eklund DE, Spielmann DC. Differential Absorption of Offset Ink Components on Coated Paper. In: 2000 TAPPI International Printing and Graphic Arts Conference, Savannah, Georgia. 2000.

4. Awaja F, Gilbert M, Kelly G, Fox B, Pigram PJ. Adhesion of polymers. Prog Polym Sci [Internet]. 2009 Sep;34(9):948-68. Available from: http://linkinghub. elsevier.com/retrieve/pii/S0079670009000501

5. Borch J. Thermodynamics of polymer-paper adhesion. A review. J Adhes Sci Technol. 1991;5(7):523-41.

6. Bollström R, Tobjörk D, Dolietis P, Salminen P, Preston J, Österbacka R, et al. Printability of functional inks on multilayer curtain coated paper. Chem Eng Process Process Intensif [Internet]. 2013 Jun;68:1320. Available from: http://dx.doi.org/10.1016/j. cep.2012.07.007

7. Öhlund T, Örtegren J, Forsberg S, Nilsson H-E. Paper surfaces for metal nanoparticle inkjet printing. Appl Surf Sci [Internet]. 2012 Oct;259:731-9. Available from: http://dx.doi.org/10.1016/j.apsusc.2012.07.112

8. Dogome K, Enomae T, Isogai A. Method for controlling surface energies of paper substrates to create paper-based printed electronics. Chem Eng Process Process Intensif [Internet]. 2013 Jun;68:21-5. Available from: http://dx.doi.org/10.1016/j.cep.2013.01.003

9. Pykönen M, Silvaani H, Preston J, Fardim P, Toivakka M. Influence of plasma activation on absorption of offset ink components into pigment-coated paper. Nord Pulp Pap Res J [Internet]. 2010;25(1):93-9. Available from: http://www.scopus.com/inward/ record.url? eid=2-s2.0-84855538438\&partnerID $=\mathrm{t}-$ ZOtx3y1

10. Forsström J, Eriksson M, Wågberg L. A new technique for evaluating ink-cellulose interactions: initial studies of the influence of surface energy and surface roughness. J Adhes Sci Technol [Internet]. 2005;19(9):783-98. Available from: http://www.tandfonline.com/doi/abs/10.1163/1568561054867846

11. Vukoje M, Jamnicki S, Rožić M. Deinkability of thermochromic offset inks. Nord Pulp Pap Res J [Internet]. 2016 Dec;31(04):692-9. Available from: http://www.npprj.se/html/np-viewarticleabstract.as$\mathrm{p} ? \mathrm{~m}=10156 \& \mathrm{mp}=762$

12. Thompson RC, Manning A, Lane J. An investigation of the effect of temperature and exposure to ultrasound on the de-inking of $\mathrm{m}$ xed recoverable office waste. 2000;2000(7):322-8.

13. Seeboth A, Lotzsch D. Thermochromic and thermotropic materials. Vol. 1, Taylor and Francis. Boca Raton, FL: CRC Press by Taylor \& Francis Group; 2013. 1-221 p.

14. Tang SLP, Stylios GK. An overview of smart technologies for clothing design and engineering. Int J Cloth Sci Technol. 2006;18(2):108-28.

15. Aitken D, Burkinshaw SM, Griffiths J, Towns AD, Ion I. Textile applications of thermochromic systems. Rev Prog Color. 1996;26:1-8.

16. Fujinami F. Patent US5500040 - Ultraviolet-curable thermochromic ink composition [Internet]. 1996. Available from: https://www.google.com/patents/ US5500040

17. Seeboth A, Klukowska A, Ruhmann R, Lötzsch D. Thermochromic Polymer Materials. Chinese J Polym Sci. 2007;25(2):123-35.

18. White MA, LeBlanc M. Thermochromism in Commercial Products. J Chem Educ. 1999;76(9):1201-5.

19. MacLaren DC, White MA. Dye-developer interactions in the crystal violet lactone-lauryl gallate binary system: implications for thermochromism. J Mater Chem [Internet]. 2003;13(7):1695-700. Available from: http://xlink.rsc.org/?DOI=B302249H

20. Seeboth A, Lotzsch D. Thermochromic Phenomena in Polymers [Internet]. Shropshire, UK: Smithers Rapra Technology Limited; 2008. 105 p. Available from: http://scholar.google.com/scholar?hl=en\&bt$\mathrm{nG}=$ Search \&q=intitle:Thermochromic+Phenomena+in+Polymers\#0

21. Vukoje M, Rožić M, Miljanić S, Pasanec Preprotić S. Biodegradation of thermochromic offset prints. Nord Pulp Pap Res J. 2017;32(2):289-98.

22. Jamnicki Hanzer S, Rožić M, Vukoje M, Jukić M, Galić A. Safety Evaluation of Deinked Pulp Containing Offset Thermochromic Inks. BioResources. 2018;13(1):678-90.

23. Rožić M, Vukoje M, Kapović D, Marošević L. Solvents interactions with thermochromic print. J Graph Eng Des [Internet]. 2017 Dec;8(2):19-25. Available from: http://www.grid.uns.ac.rs/jged/download/v8n2/jged_ v8_n2_p3.pdf

24. Żenkienwicz M. Methods for the calculation of surface free energy of solids. J Achiev Mater Manuf Eng. 2007;24(1):137-45. 
25. Shah AA, Hasan F, Hameed A, Ahmed S. Biological degradation of plastics: A comprehensive review. Biotechnol Adv. 2008;26(3):246-65.

26. Hubbe MA, Venditti RA, Rojas OJ. What happens to cellulosic fibers during papermaking and recycling? a review. 2007;2:739-88.

27. Repeta V. Influence of Surface Energy of Polymer Films on Spreading and Adhesion of UV-Flexo Inks. Acta Graph. 2013;23(3-4):79-84.

28. Shogren RL, Petrovic Z, Liu Z, Erhan SZ. Biodegradation behavior of some vegetable oil-based polymers. J Polym Environ. 2004;12(3):173-8.

29. Koivula H, Preston JS, Heard PJ, Toivakka M. Visualisation of the distribution of offset ink components printed onto coated paper. Colloids Surfaces A Physicochem Eng Asp [Internet]. 2008 Mar;317(1-3):55767. Available from: http://linkinghub.elsevier.com/ retrieve/pii/S0927775707010084

30. Leach, R.H., Pierce, R.J., Hickman, E.P., Mackenzie, M.J. and Smith HG. The Printing Ink Manual. 5th, editor. Springer; 2007.

31. Leja K, Lewandowicz G. Polymer biodegradation and biodegradable polymers - A review. Polish J Environ Stud. 2010;19(2):255-66.

32. Arutchelvi J, Sudhakar M, Arkatkar A, Doble M, Bhaduri S, Uppara PV. Biodegradation of polyethylene and polypropylene. Indian J Biotechnol. 2008;7(1):9-22. 